\title{
Commentary: Staying in the zone during aortic arch replacement
}

\author{
Leora B. Balsam, MD, ${ }^{\mathrm{a}}$ and Abe DeAnda, $\mathrm{Jr}, \mathrm{MD}^{\mathrm{b}}$
}

\footnotetext{
From the ${ }^{\text {aDivision }}$ of Cardiac Surgery, UMass Memorial Medical Center, Worcester, Mass; and ${ }^{\mathrm{b} D i v i s i o n}$ of Cardiovascular and Thoracic Surgery, University of Texas Medical Branch, Galveston, Tex.

Disclosures: Authors have nothing to disclose with regard to commercial support.

Received for publication Jan 31, 2019; accepted for publication Feb 1, 2019; available ahead of print March 16, 2019.

Address for reprints: Leora B. Balsam, MD, Division of Cardiac Surgery, UMass Memorial Medical Center, University Campus, 55 N Lake Ave, Worcester, MA 01655 (E-mail: leora.balsam@ umassmemorial.org).

J Thorac Cardiovasc Surg 2019;157:e237-8

$0022-5223 / \$ 36.00$

Copyright (c) 2019 by The American Association for Thoracic Surgery

https://doi.org/10.1016/j.jtcvs.2019.02.005
}

The tools of the trade for repair of complex pathology of the aortic arch and descending aorta have evolved dramatically in the last 20 years. This has resulted in a transition from conventional open surgical repair to hybrid procedures that use a combination of open and endovascular techniques. The sequence of first-stage arch replacement with elephant trunk followed by second-stage open replacement of the descending aorta has largely been replaced by singlestage arch replacement with frozen elephant trunk or staged arch replacement with retrograde thoracic endovascular aortic repair (TEVAR). Retrospective studies have shown that these hybrid procedures have a broader reach in an older and sicker patient population and that the likelihood of achieving a complete repair (without loss of follow-up between stages) is higher. ${ }^{1-3}$

In this issue of the Journal, Urbanski ${ }^{4}$ describes his technique for open arch replacement with a 4-branched vascular graft. His nuanced approach emphasizes the importance of planning for future operations when treating aortic disease. This includes anticipating either proximal aortic (or nonaortic cardiac) or descending or thoracoabdominal aortic surgery in the future. The main concepts in this surgical technique article are as follows: (1) A sufficient landing zone should exist after total arch replacement to allow future retrograde TEVAR. (2) How one connects the graft limbs to the supra-aortic branches will affect the ease of sewing and the length of the landing zone for future TEVAR. (3) The aorta or graft must be clampable proximally without compromising the supra-aortic branches; this will facilitate future cardiac or proximal aortic surgery. To achieve these aims, Urbanski ${ }^{4}$ anastomoses the designated cannulation branch of the 4-branched graft to the left subclavian artery. This branch is more anterior and proximal than the graft's left subclavian limb. He uses the graft's left subclavian limb for lower body perfusion instead (as an alternative cannulation branch). This approach allows a greater length of graft distal to the supra-aortic branches, branch is longer.

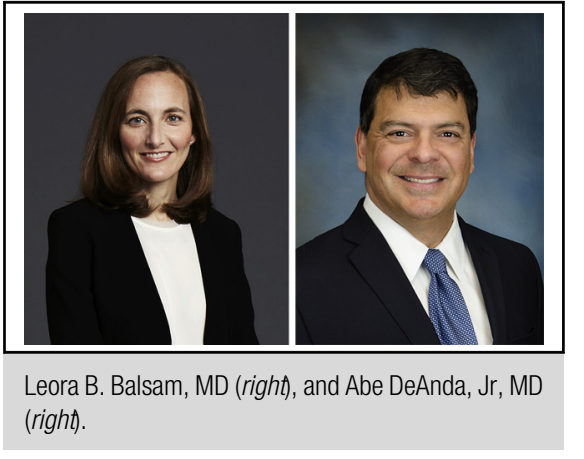

Central Message

Planning for future cardiac and aortic operations is a key principle of aortic surgery. A modified use of the 4-branched vascular graft for arch replacement may help achieve this aim.

See Article page e229.

that is, a longer landing zone for future retrograde TEVAR. Urbanski ${ }^{4}$ also notes that it is easier to sew the left subclavian anastomosis with this configuration because the graft

In an evolving field, it is important for experienced surgeons to share tips and tricks with their surgical colleagues. Dialogue between surgeons and device manufacturers is also critical for shaping existing tools into ones that are practical for the end user and optimal for the patient. Urbanski ${ }^{4}$ suggests that a change in the 4-branched graft design could improve its usability. He proposes moving the third branch to an anterior location next to the cannulation branch; this would place the origins of the 4 branches in a double row occupying a smaller area. In this configuration, the cannulation branch would be easier to oversew because it is less distal (in other words, less deep in the chest).

Urbanski ${ }^{4}$ offers one approach to treating disease of the arch and descending aorta; this technique achieves a landing zone for future TEVAR while also preserving enough tissue for aortic clamping proximal to the great vessels. Other solutions to the problem exist, and in some cases these may be preferred. For example, one well-established approach is open arch replacement with a conventional elephant trunk (as a first-stage procedure 
before second-stage open descending aortic replacement or retrograde TEVAR). ${ }^{3}$ Another is hybrid open arch replacement with frozen elephant trunk performed with contemporary grafts that include a perfusion branch, a sewing collar to facilitate distal anastomosis to the proximal descending aorta, and a device for antegrade TEVAR. ${ }^{5}$ More recently, a combined prosthesis that includes a 4-branched vascular graft, a sewing collar, and a distal stent graft has become available (Thoraflex Hybrid graft; Vascutek, Inchinnan, United Kingdom). ${ }^{6}$ A third option is arch debranching followed by antegrade or retrograde TEVAR into zone $0 .^{7}$ In many cases this can be accomplished without cardiopulmonary bypass, which has important advantages in certain patient subsets. The important point is that the solution chosen must be tailored to the patient, the disease process, the patient's anatomy, and the local resources at the institution performing the procedure. Each procedure has its own risks and benefits, and those should be matched to the specific patient.

\section{References}

1. De Rango P, Ferrer C, Coscarella C, Musumeci F, Verzini F, Pogany G, et al. Contemporary comparison of aortic arch repair by endovascular and open surgical reconstructions. J Vasc Surg. 2015;61:339-46.

2. Hiraoka A, Chikazawa G, Tamura K, Totsugawa T, Sakaguchi T, Yoshitaka H. Clinical outcomes of different approaches to aortic arch disease. J Vasc Surg. 2015;61:88-95.

3. Shrestha M, Martens A, Krüger H, Maeding I, Ius F, Fleissner F, et al. Total arch replacement with elephant trunk technique: single-centre 30-year results. Eur J Cardiothorac Surg. 2013;45:289-95; discussion 295-6.

4. Urbanski PP. Prospective planning during conventional aortic arch replacement: the role of landing zone preparation for future stent grafting. J Thorac Cardiovasc Surg. 2019; 157:e229-34.

5. Shrestha M, Bachet J, Bavaria J, Carrel TP, De Paulis R, Di Bartolomeo R, et al. Current status and recommendations for use of the frozen elephant trunk technique: a position paper by the vascular domains of EACTS. Eur J Cardiothorac Surg. 2015;47:759-69.

6. Shrestha M, Kaufeld T, Beckmann E, Fleissner F, Umminger J, Abd Alhadi F, et al. Total arch replacement with a novel 4-branched frozen elephant trunk prosthesis: single-center results of the first 100 patients. J Thorac Cardiovasc Surg. 2016;152: 148-59.e1.

7. Bavaria J, Vallabhajosyula P, Moeller P, Szeto W, Desai N, Pochettino A. Hybrid approaches in the treatment of aortic arch aneurysms: postoperative and midterm outcomes. J Thorac Cardiovasc Surg. 2013;145(3 Suppl):S85-90. 